\title{
Correction to: Remdesivir for Treatment of COVID-19: Combination of Pulmonary and IV Administration May Offer Additional Benefit
}

\author{
Duxin Sun ${ }^{1,2}$
}

Published online 2 August 2020

\section{Correction to: The AAPS Journal https://doi.org/10.1208/s12248-020-00459-8}

During the proofing process, the misspelling of "additional" occurred while changing the title of the article. The complete title should be "Remdesivir for Treatment of COVID-19: Combination of Pulmonary and IV Administration May Offer Additional Benefit".

Publisher's Note Springer Nature remains neutral with regard to jurisdictional claims in published maps and institutional affiliations.

The online version of the original article can be found at https:// doi.org/10.1208/s12248-020-00459-8

${ }^{1}$ Department of Pharmaceutical Sciences, College of Pharmacy, University of Michigan, Ann Arbor, MI 48109, USA.

${ }^{2}$ To whom correspondence should be addressed. (e-mail: duxins@umich.edu) 